\title{
A POPULAÇÃO NATIVA DA AMÉRICA DO SUL*
}

Julian H. Steward**

\begin{abstract}
A densidade por unidade de área da população é uma medida aproximada do sucesso das atividades de subsistência na área e, até certo ponto, é correlacionada ao desenvolvimento cultural. Porém, ela não fornece esclarecimentos suficientes sobre problemas culturais, porque mera densidade mostra as populações apenas em um sentido médio ou estatístico, como se fossem esparramadas igualmente pela região. De fato, grandes áreas foram temporária e permanentemente não povoadas, enquanto as pessoas se juntavam em bandos ou em comunidades. $\mathrm{Na}$ verdade, é o tamanho, a composição e a permanência dessas comunidades que proporcionam o pano de fundo dos padrões sóciopolíticos e do comportamento cultural. [Nesse artigo] a primeira seção fornecerá as densidades populacionais; a seção subseqüente relacionará a composição da colônia aos tipos sócio-políticos através de dados sobre o tamanho da comunidade.
\end{abstract}

\section{Problemas metodológicos}

As dificuldades metodológicas, inerentes aos estudos da população americana nativa, são evidentes diante das discrepâncias existentes entre os resultados de cientistas confiáveis. Números totais para o hemisfério variam de 8.400.000 de Kroeber (1939) (um número menor daquele de Ricketson (1937) que chega a 13.000.000 apenas para Yucatán) até os 40.000.000-50.000.000 de Rivet (1924) e

(*) Tradução e revisão técnica: Profs. Thomas Bonnici e Francisco S. Noelli, Universidade Estadual de Maringá.

(**)Originalmente publicado In: Julian H. Steward (Ed.) Handbook of South American Indians, v. 5. The Comparative Ethnology of South American Indians. Washington: Smithsonian Institution/Bureau of American Ethnology, Bulletin 143, 1949: 655-668.
Sapper (1924) e os 50.000.000-75.000.000 de Spinden (1928). Os totais da América do Sul variam de 4.300.000 de Kroeber aos 25.000.000 de Rivet. Means (1931) calcula entre 16.000 .000 a 32.000.000 apenas para os Andes. A tabela 1 mostra a decomposição destas estimativas. É obvio que ou os dados ou os métodos são falhos.

Os estudos populacionais anteriores analisaram principalmente a América do Norte e a América Central. Todas as estimativas da América do Sul, exceto aquelas de Rosenblat (1945), que cuidadosamente investigou fontes originais e algumas estimativas de áreas limitadas, são feitas por analogia com a América do Norte ou da América Central, ou simplesmente por suposição.

Rosenblat calcula a partir da população moderna em 1940, e retrocede para 1825,1650 , 1570 e 1492 . Ele aceita as estimativas contemporâneas de cada período: todavia, 1570 gerou dados sobre apenas poucas áreas, e 1492 é estimada por uma extensão hipotética da curva populacional. Seu método mostra detalhadamente apenas o Haiti e Santo Domingo.

Rivet (1924: 599-602) afirma que, na América do Norte, o número de aborígenes foi reduzido de 1.148.000 para um terço da presente população de 403.000 . Supondo uma redução idêntica pelo hemisfério, ele multiplica a presente população por 3 para calcular a figura dos nativos, sem levar em consideração as diferenças locais.

Sapper (1924), um geógrafo, baseia seus cálculos na presumível produtividade de tipos diferentes no uso da terra: nas áreas de caça, pesca e coleta, a população é esparsa; nas áreas de cultivo, especialmente nas planícies quentes do México, América Central e América do Sul, a população é densa. Por exemplo, considera-se que a Guatemala moderna e a Guatemala no tempo dos aborígines tenham tido aproximadamente a mesma população, porque os vários modos agrícolas são semelhantes.

As estimativas de Kroeber para a América do Norte são principalmente baseadas nos 
TABELA 1

Estimativas das Populações Nativas Americanas

\begin{tabular}{|c|c|c|c|c|}
\hline \multicolumn{5}{|c|}{ Estimativa Populacional conforme ${ }^{1}$} \\
\hline Área & Sapper (1924) & Rosenblat (1945) & Kroeber (1939:131-181) & Steward $^{2}$ \\
\hline Norte do México & $2.000 .000-3.500 .000$ & 1.000 .000 & 1.000 .880 & 1.000 .880 \\
\hline México & $12.000 .000-15.000 .000$ & 4.500 .000 & 3.000 .000 & 4.500 .000 \\
\hline Índias Ocidentais & $3.000 .000-4.000 .000$ & 300.000 & 200.000 & 225.000 \\
\hline América Central & $5.000 .000-6.000 .000$ & 8.000 .000 & $-{ }^{3}$ & 736.000 \\
\hline Total & $20.000 .000-25.000 .000$ & 5.600 .000 & - & 5.461 .880 \\
\hline América do Sul & & & & \\
\hline Andes $^{4}$ & $12.000 .000-15.000 .000$ & 4.750 .000 & 3.000 .000 & 6.131 .000 \\
\hline $\begin{array}{l}\text { Restante da América } \\
\text { do Sul }\end{array}$ & $3.000 .000-5.000 .000$ & 2.035 .000 & 3.334 .000 & 2.898 .000 \\
\hline Total & $15.000 .000-20.000 .000$ & 6.785 .000 & 4.300 .000 & 9.129 .000 \\
\hline $\begin{array}{l}\text { Total para o } \\
\text { Hemisfério }\end{array}$ & $37.000 .000-48.500 .000$ & 13.385 .000 & 8.400 .000 & 15.590 .880 \\
\hline
\end{tabular}

(1) Todas são para aproximadamente 1492 .

(2) A estimativa para a América do Norte segue Kroeber (1939); México é de Rosenblat (1945); outras estimativas serão dadas em detalhe abaixo. Uma estimativa preliminar foi dada por Steward (1945).

(3) América Central é incluída na América do Sul.

(4) Da Colômbia ao Chile.

cálculos de Mooney; para outras áreas foram feitas através de uma comparação com a América do Norte, levando em consideração as áreas culturais e naturais. Kroeber supõe que: 1) a maioria das estimativas contemporâneas, feitas especialmente pelos primeiros administradores e missionários espanhóis, eram muito altas; 2) o etnólogo competente poderia corrigir tais estimativas no caso de uma área bem conhecida; 3 ) as populações modernas dão alguma indicação das populações nativas, mas a taxa de crescimento não é a mesma em todos os lugares; 4) uma ecologia rica geralmente significa uma maior densidade de nativos, mas fatores como ferramenta de ferro e solos friáveis devem ser levados em consideração quando se comparam as densidades moderna e nativa; 5) uma rica cultura é normalmente indício de uma alta densidade.

Dados sobre a demografia na América do Sul mostram que as estimativas feitas por qualquer método apenas se aproximam da exatidão, e a margem de erro sempre será muito grande, talvez até cinquienta por cento. As estimativas contemporâneas para os primeiros períodos foram dadas principalmente por soldados e missionários $\mathrm{e}$, às vezes, por administradores. A suspeita de Kroeber sobre tais cálculos é justificável no caso de soldados que, com certeza, exageraram no número de seus inimigos. As estimativas missionárias de tribos independentes tendem ao exagero. A contagem cuidadosa de índios nas estações missionárias parece ser confiável e freqüentemente é a nossa única fonte; esses cálculos não enumeram os índios isolados; e existe a tendência de colocar juntos os índios de tribos diferentes. $O$ valor das estimativas dos administradores varia: nos Andes centrais parece que foram baseadas em cálculos cuidadosos de censos, mas a taxa de pagadores de tributo para a população inteira variava de 5 a 1 para 2 a 21 (Rosenblat 1945).

Referente à floresta tropical e às áreas do Caribe temos muito poucas estimativas contemporâneas. Os primeiros números podem variar entre cinquienta a duzentos anos após a tribo ter sido inicialmente contatada pelos brancos; doenças, guerras, escravidão, assimilação cultural racial e outros fatores já 
haviam reduzido a população pela metade ou mais e, em alguns casos, o fizeram completamente. Os Omágua foram reduzidos de 15.000 a 7.000 entre 1641 e 1681 , e os índios de Hispaniola foram quase extintos no curto período de uma geração.

A população moderna índia é um índice não-confiável da população aborígene. Isto acontece não apenas porque cada área tem uma curva populacional distinta, mas porque os censos modernos têm encontrado grandes dificuldades em contar índios em áreas remotas. Ademais, há na América Hispânica uma tendência para classificar os índios mais na base cultural do que racial. Um índio é considerado uma pessoa que vive como índio, especialmente aquele que fala a língua indígena; quando adquire suficientemente a cultura européia, ele passa para a categoria de mestiço, crioulo, ladino ou caboclo, como os índios parcialmente assimilados são chamados, embora racialmente ele seja completa ou majoritariamente índio. $\mathrm{O}$ método de projetar a curva populacional do presente ao passado, ou seja, para tempos aborígenes, poderia ser válido apenas se a curva tivesse sido inicialmente estabelecida em estimativas confiáveis em todos os períodos. Mesmo assim, sua aplicabilidade a outras tribos para os quais foi construída, é um ponto questionável, porque muitos fatores são envolvidos: se os índios continuaram nas missões; efeitos de doença; fatores especiais de sua cultura, ambiente e contato com o branco. Portanto, enquanto os Omágua foram reduzidos à metade em 40 anos, no século 17, seus vizinhos, os Kokáma mantiveram os números nativos quase até hoje.

O método presente utiliza os dados mais antigos que parecem ser confiáveis - em alguns casos, os relatórios de missionários e administradores, em outros, os relatos de viajantes - e estende a densidade calculada para uma tribo específica a outras que possuíam culturas semelhantes e moravam em áreas semelhantes. Como as tribos parecem ter declinado, em termos gerais, ao tempo que as estimativas eram feitas, as densidades calculadas, embora admita-se certo exagero, provavelmente tendem a ser menores do que maiores.

\section{Densidades nativas}

As estimativas presentes são meros cálculos e devem ser consideradas preliminares. Algumas áreas, completamente desconhecidas, são estimadas por analogia com áreas vizinhas para as quais existem amostras razoáveis. Em geral, isto dá um quadro coerente para que a margem de erro em certas áreas provavelmente não seja mais de que $10 \%$ ou $20 \%$. Em algumas áreas o erro pode chegar a $100 \%$; todavia, diminuindo o erro a tanto já é uma façanha considerável, se são levadas em conta as estimativas anteriores. A necessidade óbvia é a utilização plena da fonte material numa contagem tribo a tribo e área por área, igual àquela de Kubler (1946: 334-341) e Rowe (1946: 184) para os Andes.

O Mapa 1 segue o mapa de Kroeber para a América do Norte (Kroeber 1939) e mostra o número de pessoas por $100 \mathrm{~km}^{2}$.

As estimativas para as tribos Marginais do sul são provavelmente exatas, embora fossem feitas muitos anos depois do contato. Se fossem erradas, seriam muito baixas. Estimativas mais antigas dão os números dos Guarani e dos Chaco, que parecem ser razoáveis, mas os Abipón poderiam ter uma densidade 5 , revista para 15.

As densidades dos Araucano e as de Chilotán, estas últimos maiores do que as dos Andes centrais, são surpreendentemente altas. Mesmo uma redução da estimativa dos Araucano à metade deixaria um número acima das densidades das tribos vizinhas; mas os Araucano modernos são 300.000 . Se a população nativa araucana de 1.000 .000 não é um erro grande (veja Rosenblat 1945: 77-78), o Chile Central durante a agricultura indígena era muito mais produtivo do que se admitia até agora. Em contraste, os números de atacameños, baseados numa amostra pequena, são surpreendentemente baixos. Poucas áreas dos desertos ao norte do Chile são habitadas e o total de atacameños não poderia ter sido mais do que 40.000 . Os Diaguita deveriam ter tido uma densidade entre 13 , calculada para os atacameños, e 15, estabelecida para os Comechingón.

As tribos Marginais das planícies do Brasil oriental são em grande parte desconhecidas. A densidade média de 10 por $100 \mathrm{~km}^{2}$, 


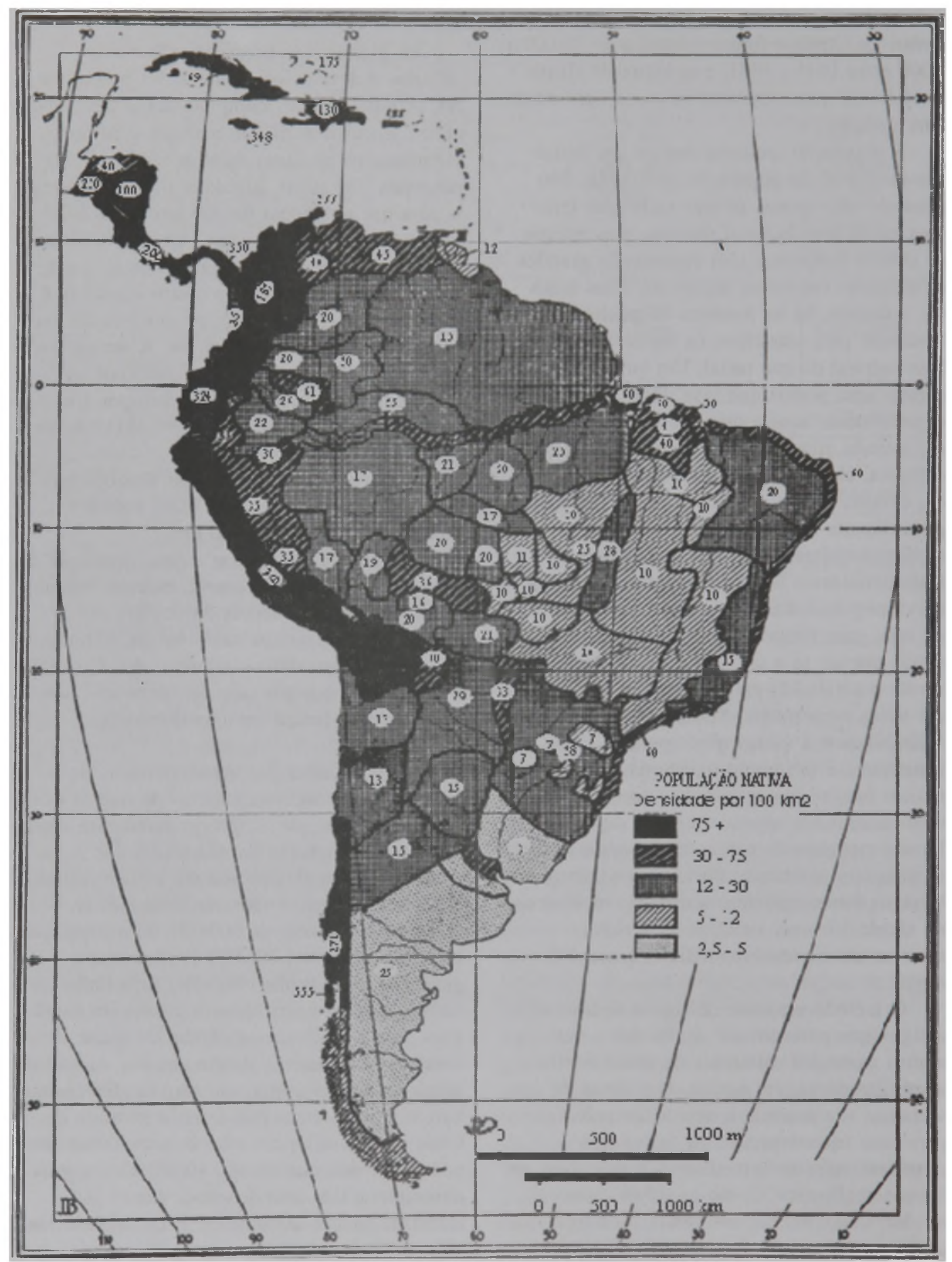

Mapa 1 
baseada em várias amostras da área do alto Xingu-Tapajós, estende-se às tribos Jê. $A$ densidade maior de 15 para os Botocudo e seus vizinhos na costa brasileira é uma revisão para cima das várias amostras recentes desses povos. Por contraste, julgando-se pelos números dos Tupinambá, os Tupi da costa tinham uma densidade nativa de 60 .

Para as tribos da floresta tropical da bacia da Amazônia, algumas amostras independentes consistentemente variam entre 17 e 25 . Há algumas áreas na floresta tropical que não seguem o padrão geral. $\mathrm{O}$ território sul do alto rio Guaporé na Bolívia oriental tinha 36 pessoas por $\mathrm{km}^{2}$, o que parece um número relativamente bom. A não ser que estes números sejam muito altos, a densidade de 20 dos Yunga poderia ser muito baixa. Parece que os Yunga têm um número muito baixo quando comparado com aquele das montanhas ao norte; possivelmente a população dos Yunga, que manteve contato com os brancos quase desde o início, ficou reduzida à metade quando as estimativas foram feitas. $O$ número da Montaña é muito alto em comparação ao das terras baixas da Amazônia. A não ser que os missionários tenham errado numa maneira muito consistente nas várias estimativas independentes sobre a Montaña, pode-se suspeitar que algumas estimativas das terras baixas, geralmente posteriores, são baixas demais. Os Witoto constituem uma ilha de grande densidade no meio de pessoas comparativamente muito raras. Os números de observadores confiáveis como Preuss e Whiffen significam que as estimativas para os povos vizinhos são muito baixas; por enquanto, tal inconsistência pode ser mantida.

No que diz respeito a Guiana, certamente os números são muito baixos. Necessitam-se números sobre o período de contato. Amostras recentes dão uma densidade de cerca de 10 por $100 \mathrm{~km}^{2}$; o número dos nativos poderia ser $50 \%$ a mais, ou superior. É uma questão discutida se a costa pantanosa tinha uma alta densidade fora do comum.

A melhor fonte para a Venezuela é Humboldt (1862) cujas observações realizadas em 1800 dão amostras de densidade de $38 / 100 \mathrm{~km}^{2}$. A população nativa era muito maior, mas é impossível dizer quanto sem a utilização das fontes do período de contato. A densidade poderia ter sido $45 / 100 \mathrm{~km}^{2}$.

A Colômbia também necessita de fontes antigas. A estimativa atual aceita 300.000 para os Chibcha e 700.000 - uma densidade de 184 - para o resto da Colômbia, um total de 1.000.000, embora algumas estimativas sobre os Chibcha apenas cheguem a $\mathbf{1} .000 .000$. Uma estimativa confiável de 1586 dá à Colômbia o número de 715.000 (Rosenblat 1945: 77-78); 1.000.000 para todos os nativos na Colômbia parece ser razoável em comparação com o do Peru, e provavelmente não tão grande. Alguns cronistas estimam de 100.000 a 500.000 somente no vale Popayán, uma densidade de 500 a $2.500 / 100 \mathrm{~km}^{2}$.

$\mathrm{O}$ número nativo nas montanhas do Equador é calculado apenas por analogia. $\mathrm{O}$ meio milhão da população nativa, muito parecido ao número dos índios atuais, dá uma densidade de 300 quando comparada com os 390 do Peru por $100 \mathrm{~km}^{2}$. Certamente esta figura não é muito baixa; se, no Equador e no Peru, há mais índios atualmente do que durante a conquista, o número torna-se muito grande.

A América Central também necessita de estimativas baseadas nos primeiros cronistas. A atual população indígena, que em muitas áreas ou foi extinta ou muito reduzida, dá muita pouca luz sobre os números nativos. As poucas amostras mais antigas sugerem que a população era muito densa no Panamá oriental, ou seja, 300 pessoas por $100 \mathrm{~km}^{2}$, que diminuía em direção ao oeste. Costa Rica, El Salvador e as montanhas ao sul da Guatemala tinham uma densidade maior $\left(200 / 100 \mathrm{~km}^{2}\right)$ do que a Nicarágua ou o norte de Honduras $\left(40 / 100 \mathrm{~km}^{2}\right)$.

$O$ Caribe tinha uma grande população, embora seu tamanho freqüentemente tenha sido exagerado. Segui as estimativas conservadoras de Rosenblat, embora o número que ele dá para Hispaniola mostre uma densidade de 767/100 $\mathrm{km}^{2}$, o dobro de qualquer outra área na América. As Antilhas Menores chegam a uma densidade acima de $500 / 100 \mathrm{~km}^{2}$, a julgar por certas amostras. Por contraste, Cuba, que os índios Aruák compartilhavam com os Ciboney primitivos, tinha uma densidade de apenas $59 / 100 \mathrm{~km}^{2}$.

Na Tabela 2 os dados foram retirados dos artigos do Handbook of South American Indians, exceto quando a fonte é indicada. 
TABELA 2

\begin{tabular}{|c|c|c|c|c|}
\hline \multicolumn{5}{|c|}{ Números das populações nativas e densidades das tribos da América do Sul } \\
\hline Área & População & $\begin{array}{c}\text { Tamanho em } \\
\text { unidades de } 100 \mathrm{~km}^{2}\end{array}$ & $\begin{array}{c}\text { Pessoas } \\
\mathrm{p} / 100 \mathrm{~km}^{2}\end{array}$ & Fontes e comentários \\
\hline $\begin{array}{l}\text { Tribos Marginais } \\
\text { Marginais do Sul } \\
\text { Arquipélago }\end{array}$ & 9. 000 & 1.051 & 9 & $\begin{array}{l}\text { Chono, } 1.000 \text {; Alakaluf, } 400 \text { após } 1900 ; \\
\text { Yaghan, } 3.000,1875 \text {; Ona, } 2.000,1875-1900\end{array}$ \\
\hline Pampa - Patagônia & 36.125 & 14.450 & 2.5 & Várias estimativas no século XIX \\
\hline Querandí & 4.000 & 1.000 & 4 & \\
\hline Comechingón-Huarpe, etc.. & 52.550 & 3.570 & 15 & $\begin{array}{l}\text { Estimativa dos Comechingón nativos: } 30.000 \\
\text { (Serrano 1945) }\end{array}$ \\
\hline Charrua-Caracara & 9. 000 & 3.000 & 3 & Por analogia com os Pampa \\
\hline \multicolumn{2}{|c|}{ Total, Marginais do Sul 110.675} & \multicolumn{3}{|l|}{23.071} \\
\hline Chaco Ocidental & 186.400 & 4.320 & 29 & $\begin{array}{l}\text { Totais mais antigos para as principais tribos } \\
\text { (Métraux 1946) }\end{array}$ \\
\hline Bororo & 16.000 & 1.600 & 10 & $\begin{array}{l}\text { Por analogia; as estimativas recentes parecem } \\
\text { excessivamente baixas }\end{array}$ \\
\hline Kayapó do Sul-Guató & 59.000 & 5.900 & 10 & Por analogia; sem dados \\
\hline Kaingang & 17.500 & 2.500 & 7 & Amostra recente; pode ser muito baixa \\
\hline Bakairi & 6.000 & 600 & 10 & Por analogia; sem dados \\
\hline Nambikwára & 22.000 & 1.100 & 20 & Boas estimativas (Lévi-Strauss 1948) \\
\hline Alto Xingu & 10.000 & 1.000 & 10 & $\begin{array}{l}\text { Analogia com Nambikwára, redução conserva- } \\
\text { dora; excessivamente baixos os } 3.000 \text { de von } \\
\text { den Steinen }\end{array}$ \\
\hline Jê Centrais e do Noroeste & 98.000 & 9. 800 & 10 & Amostras recentes deram 6 a 8 por $100 \mathrm{~km}^{2}$ \\
\hline Kreié-Timbira & 1.440 & 160 & 9 & Por analogia com outros Jê \\
\hline Timbira & 22.000 & 2.200 & 10 & Sem dados; por analogia \\
\hline Jeicó & 10.000 & 1.000 & 10 & Sem dados; por analogia \\
\hline Botocudo, etc.. & 43.500 & 2.900 & 15 & $\begin{array}{l}\text { Estimativas do último século dão densidade } \\
\text { de } 11 \text { a } 14 \text { por } \mathrm{km}^{2}\end{array}$ \\
\hline Tapirapé & 4.000 & 160 & 25 & $\begin{array}{l}\text { Estimativa de 1910: 1.000; redução dos Karajá } \\
\text { em } 1910 \text { foi estimada em um quarto da original }\end{array}$ \\
\hline Karajá & 57.000 & 2.000 & 28 & $\begin{array}{l}\text { Krause estimou } 100.000 \text { para } 1845 \text {; redução } \\
\text { pela metade }\end{array}$ \\
\hline Tremenbé & 21.000 & 700 & 30 & $\begin{array}{l}\text { Sem dados; densidade foi provavelmente a } \\
\text { metade dos Tupi da costa }\end{array}$ \\
\hline Total, Brasil oriental & $\mathbf{3 8 7 . 4 4 0}$ & 700 & & \\
\hline \multicolumn{5}{|l|}{ Marginais da Amazônia } \\
\hline Mura & 30.000 & 1.400 & 21 & $\begin{array}{l}\text { Redução à metade da estimativa mais antiga } \\
\text { de } 60.000 \text { habitantes nativos }\end{array}$ \\
\hline Província de Mainas & 42.500 & 1.900 & 22 & Estimativas de missionários \\
\hline Caríjona & 19.400 & 970 & 20 & Analogia; sem dados \\
\hline Outros & & & & $\begin{array}{l}\text { Incluídos com tribos vizinhas por carência } \\
\text { de dados }\end{array}$ \\
\hline $\begin{array}{l}\text { Total, Marginais da } \\
\text { A mazônia }\end{array}$ & 91.900 & 4.270 & & \\
\hline
\end{tabular}


TABELA 2 (cont.)

\begin{tabular}{|c|c|c|c|c|}
\hline \multicolumn{5}{|c|}{ Números das populações nativas e densidades das tribos da América do Sul } \\
\hline Área & População & $\begin{array}{c}\text { Tamanho em } \\
\text { unidades de } 100 \mathrm{~km}^{2}\end{array}$ & $\begin{array}{l}\text { Pessoas } \\
\mathrm{p} / 100 \mathrm{~km}^{2}\end{array}$ & Fontes e comentários \\
\hline $\begin{array}{l}\text { Tribos da Floresta Tropical } \\
\text { Chaco Oriental: } \\
\text { Abipones e vizinhos }\end{array}$ & 50.250 & 3.350 & 15 & $\begin{array}{l}\text { Totais mais antigos das principais tribos } \\
\text { (Métraux 1946) }\end{array}$ \\
\hline Payaguá, Chané, Mbayá & 30.000 & 900 & 33 & Totais mais antigos (Métraux 1946) \\
\hline Total do Chaco Oriental & \multicolumn{4}{|c|}{$80.250 \quad 4.250$} \\
\hline $\begin{array}{l}\text { Tupi-Guarani } \\
\text { Paraguai-Brasil }\end{array}$ & 200.000 & 7.200 & 28 & $\begin{array}{l}\text { Estimativa de } 300.000 \text { Guarani mortos ou } \\
\text { capturados na Conquista, reduzidos para } 200.000 \text {; } \\
\text { ou } 30 \text { missões com } 6.000 \text { cada em } 1708\end{array}$ \\
\hline Delta do Paraná & 24.000 & 800 & 30 & Por comparação com os Tupi da costa \\
\hline $\begin{array}{l}\text { Região do Alto Rio São } \\
\text { Francisco }\end{array}$ & 49. 000 & 4.000 & 10 & Sem dados; analogia com a área Jê \\
\hline Karirí e vizinhos & 65.500 & 6.550 & 10 & Sem dados; analogia com a área Jê \\
\hline $\begin{array}{l}\text { Tupi da costa sul do } \\
\text { Amazonas }\end{array}$ & 189.000 & 3.150 & 60 & $\begin{array}{l}4.200 \mathrm{~km} \text { de costa, por } 75 \mathrm{~km} \text { de profundidade. } \\
\text { A amostra Tupinambá deu } 27.000 \text { pessoas em } \\
45.000 \mathrm{~km}^{2} \text {. Ilha do Maranhão, densidade de } \\
906 \text { por } 100 \mathrm{~km}^{2} \text { (Métraux } 1948 \text { ) }\end{array}$ \\
\hline Tenetehara & 60.800 & 1.520 & 60 & $\begin{array}{l}\text { Por analogia com os Tupi da costa; número } \\
\text { desconhecido de Amanayé e Turiwára não } \\
\text { foram computados na área }\end{array}$ \\
\hline Tupi do baixo Amazonas & 100,00 & 4.000 & 25 & $\begin{array}{l}\text { Âmbito da densidade Mawé; Amostra Mawé } \\
\text { em } 1939 \text { deu } 25 \text { por } 100 \mathrm{~km}^{2} \text {. Total pode } \\
\text { ser visto abaixo }\end{array}$ \\
\hline Apiaká-Kayabi & 18.000 & 1.600 & 11 & $\begin{array}{l}\text { Estimativa provavelmente segura de } 16.000 \\
\text { Apiaká, } 2.000 \text { Kayabi }\end{array}$ \\
\hline Mundurukú & 36.200 & 1.800 & 20 & $\begin{array}{l}\text { Estimativa de Martius por volta de } 1888 \text {, o } \\
\text { dobro de Tocantins em } 1877\end{array}$ \\
\hline Parintintin-Kagwhív & 25.500 & 1.500 & 17 & Por analogia com vizinhos Tupi \\
\hline \multicolumn{5}{|c|}{ Total Tupi-Guarani $\quad \mathbf{7 6 8 . 0 0 0}$} \\
\hline Rio Amazonas & & & & $\begin{array}{l}\text { Essas estimativas levam em conta } 50 \mathrm{~km} \text {, } \\
\text { ambos os lados do rio }\end{array}$ \\
\hline Kokáma & 12.000 & 400 & 30 & $\begin{array}{l}\text { Estimativas de missionários. Hoje, cerca de } \\
10.000\end{array}$ \\
\hline Omágua & 16.000 & 800 & 20 & $\begin{array}{l}\text { Estimativas de missionários, } 15.000 \mathrm{em} \\
1641 ; 7.000 \text {, em } 1681\end{array}$ \\
\hline $\begin{array}{l}\text { Amazonas abaixo dos } \\
\text { Omágua }\end{array}$ & 72.000 & 1.800 & 40 & $\begin{array}{l}\text { Sem dados; analogia com os Tupi da costa e } \\
\text { com o Alto Amazonas; Carvajal notou } \\
\text { aldeias grandes abaixo da foz do Içá }\end{array}$ \\
\hline Aruã (Marajó) & 30.000 & 500 & 60 & Sem dados; por analogia com os Tupi da costa \\
\hline Total do Amazonas & 130.000 & \multicolumn{3}{|l|}{3.500} \\
\hline $\begin{array}{l}\text { Sudoeste da Amazônia } \\
\text { Juruá-Purús }\end{array}$ & 139.400 & 7.200 & 17 & $\begin{array}{l}\text { Por analogia com vizinhos; brancos e índios } \\
\text { atuais são cerca de } 100.000\end{array}$ \\
\hline Norte do Guaporé & 46.000 & 2.300 & 20 & Sem dados; por analogia com os vizinhos \\
\hline Sul do Rio Guaporé & 72.160 & 1.950 & 36 & $\begin{array}{l}\text { Média de várias estimativas alcançam de } 25 \\
\text { a } 45 \text { por } \mathbf{k m}^{2}\end{array}$ \\
\hline $\begin{array}{l}\text { Total do Sudoeste da } \\
\text { Amazônia }\end{array}$ & 257.560 & \multicolumn{3}{|l|}{11.450} \\
\hline
\end{tabular}


TABELA 2 (cont.)

\begin{tabular}{|c|c|c|c|c|}
\hline \multicolumn{5}{|c|}{ Números das populações nativas e densidades das tribos da América do Sul } \\
\hline Área & População & $\begin{array}{c}\text { Tamanho em } \\
\text { unidades de } 100 \mathrm{~km}^{2}\end{array}$ & $\begin{array}{l}\text { Pessoas } \\
\mathrm{p} / 100 \mathrm{~km}^{2}\end{array}$ & Fontes e comentários \\
\hline $\begin{array}{l}\text { Bolívia Oriental } \\
\text { Tacanans }\end{array}$ & 25.000 & 1.250 & 20 & $\begin{array}{l}\text { Estimativa total das missões entre } 40 \text { e } 150 \\
\text { anos atrás: } 18.000 \text {; talvez } 2 / 3 \text { seriam em missões }\end{array}$ \\
\hline Província de Chiquitos & 42.000 & 2.000 & 21 & $\begin{array}{l}\text { Estimativa de } 23.788 \text { em } 1766,200 \text { anos } \\
\text { depois do contato }\end{array}$ \\
\hline Província de Mojos & 6.000 & 400 & 15 & Estimativa para 1680 \\
\hline Paresí & 5.000 & 50 & 10 & \\
\hline Yungas & 31.000 & 1.550 & 20 & $\begin{array}{l}\text { Estimativas são muito baixas; densidade de } \\
20 \text { por } 100 \mathrm{~km}^{2} \text { é por analogia }\end{array}$ \\
\hline Chiriguano & 48.000 & 800 & 60 & Estimativa mais antiga razoavelmente acurada \\
\hline Total da Bolívia Oriental & \multicolumn{4}{|c|}{157.0006 .500} \\
\hline $\begin{array}{l}\text { Tribos da Floresta Tropical } \\
\text { (continuação) } \\
\text { Montaña: } \\
\text { Ucayali-Madeira }\end{array}$ & 31.740 & 1.800 & 17 & Censo de 1940 \\
\hline Kampa & 20.000 & 510 & 38 & $\begin{array}{l}\text { Estimativa das missões do século XVII; } \\
\text { censo de } 1940 \text { também deu } 20.000\end{array}$ \\
\hline Huallaga-Ucayali & 105.070 & 2.765 & 38 & $\begin{array}{l}\text { Estimativas amostrais de missionários; analogia } \\
\text { com vizinhos }\end{array}$ \\
\hline Jíbaro & 26.600 & 700 & 38 & Stirling (1938: 28-38). \\
\hline Kofán, Quijo, Kanelo & 25.000 & 255 & 100 & $\begin{array}{l}\text { Estimativa de missionários; veja Rosenblat } \\
(1945: 77-78)\end{array}$ \\
\hline Total da Montaña & \multicolumn{4}{|c|}{$208.750 \quad 10.075$} \\
\hline $\begin{array}{l}\text { Noroeste da Amazônia } \\
\text { Amazonas-Rio Negro }\end{array}$ & 71.250 & 2.500 & 25 & $\begin{array}{l}\text { Foi usada como amostra uma estimativa } \\
\text { nativa mais conservadora }\end{array}$ \\
\hline Tukanos ocidentais & 16.000 & 800 & 20 & $\begin{array}{l}\text { Estimativa de } 1635 \text { deu densidade de } 15 \text { por } \\
100 \mathrm{~km}^{2} \text {, ajustada para } 20\end{array}$ \\
\hline Witoto, etc.. & 67.000 & 1.000 & 67 & $\begin{array}{l}\text { Cf. Handbook, v. 3, estimativas são para } \\
\text { cima, comparadas aos vizinhos }\end{array}$ \\
\hline Uauapés-Caquetá & 45.000 & 2.250 & 20 & $\begin{array}{l}\text { Total dos Tukano em } 1900 \text { é } 8,700 \text { ou } 10 \text { pessoas } \\
\text { por } 100 \mathrm{~km}^{2} \text {; densidade nativa é provavelmente } \\
\text { o dobro }\end{array}$ \\
\hline Colômbia Oriental & 70.500 & 3.525 & 20 & Por analogia \\
\hline \multicolumn{5}{|l|}{$\begin{array}{l}\text { Total, Noroeste da } \\
\text { Amazônia } \\
\end{array}$} \\
\hline $\begin{array}{l}\text { Guianas } \\
\text { Norte da Amazônia, } \\
\text { Guianas, }\end{array}$ & 213.750 & 14.250 & 15 & $\begin{array}{l}\text { Amostras modernas dão densidades ao redor } \\
\text { de } 10 \text { pessoas por } 100 \mathrm{~km}^{2} \text {; nativos devem } \\
\text { ser o dobro, talvez mais }\end{array}$ \\
\hline Warrau & 6.300 & 525 & 12 & Gumilla 1791 \\
\hline \multicolumn{5}{|c|}{$220.050 \quad 14.775$} \\
\hline
\end{tabular}


TABELA 2 (cont.)

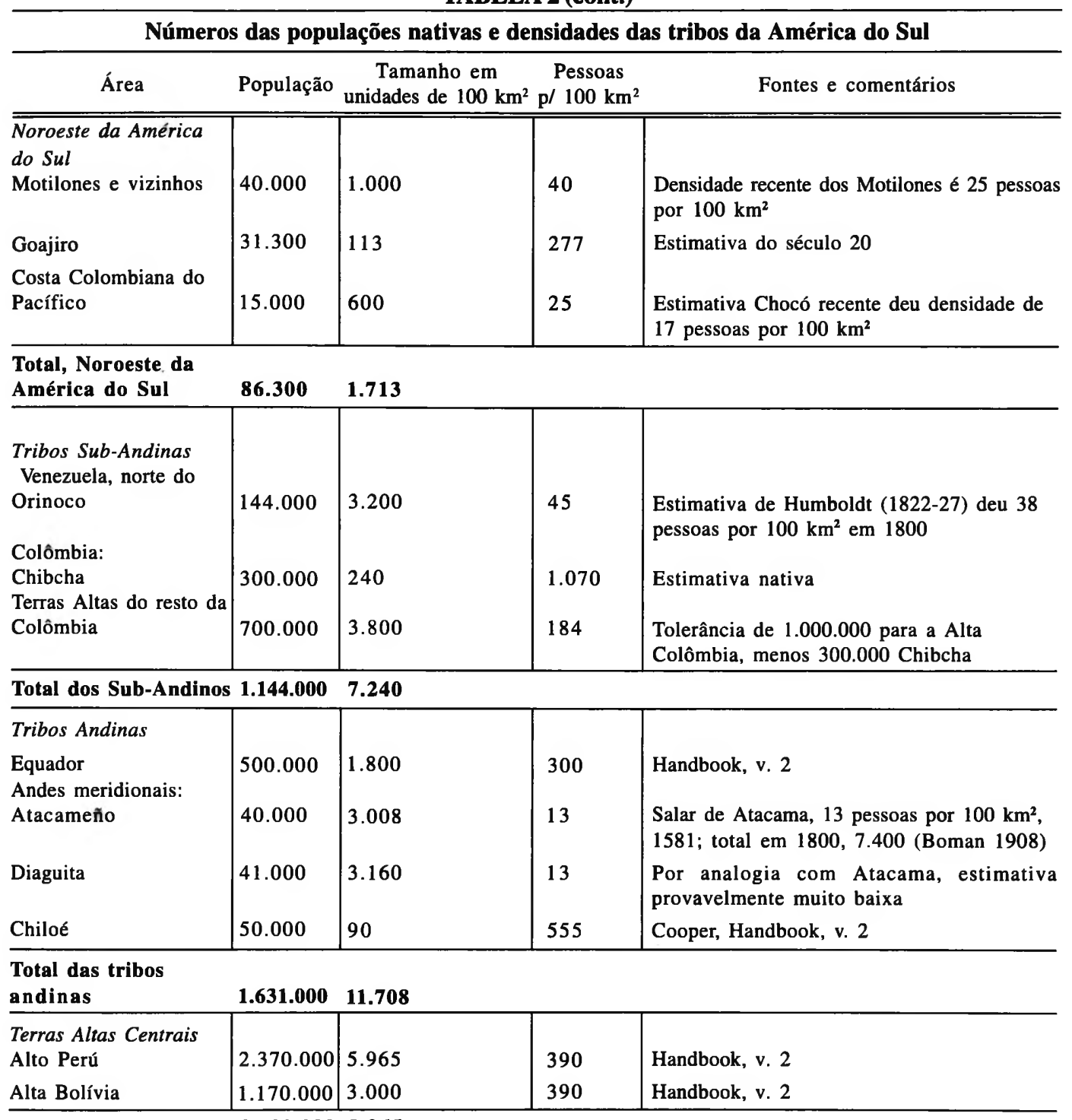

Total, Andes Centrais 3.500 .0008 .965

Total da

América do Sul $\quad 9.228 .735182 .507$

\section{Densidade, Cultura e Ecologia}

As densidades populacionais no Mapa 1 representam aproximações de números, embora possam ter um erro de 10 a $100 \%$. As densidades relativas são muito mais importantes para os problemas culturais, e o sentido de um erro é muito reduzido se as densidades relativas são consideradas. Por exemplo, através de estimativas atuais, os Andes centrais tinham cerca de 150 vezes a densidade da Patagônia. Se a população da Patagônia fosse duplicada e aquela dos Andes reduzida à metade, o primeiro aproximaria a quarenta vezes a densidade do último, que ainda ficará muito importante em termos de números de popula- 
TABELA 2 (cont.)

\begin{tabular}{|c|c|c|c|c|}
\hline \multicolumn{5}{|c|}{ Números das populações nativas e densidades das tribos da América do Sul } \\
\hline Área & População & $\begin{array}{l}\text { Tamanho em } \\
\text { unidades de } 100 \mathrm{~km}^{2}\end{array}$ & $\begin{array}{l}\text { Pessoas } \\
\mathrm{p} / 100 \mathrm{~km}^{2}\end{array}$ & Fontes e comentários \\
\hline $\begin{array}{l}\text { América Central } \\
\text { Paramá Oriental }\end{array}$ & 150.000 & 500 & 300 & $\begin{array}{l}\text { Densidade provável próxima dos Kuna moder- } \\
\text { nos, } 350 \text { por } 100 \mathrm{~km}^{2}\end{array}$ \\
\hline Panamá Ocidental & 74.600 & 373 & 200 & $\begin{array}{l}\text { População do Panamá adelgaçando em direção } \\
\text { ao Ocidente, com a densidade Chanagueña de } \\
125 \text { em } 1709\end{array}$ \\
\hline Costa Rica & 119. 400 & 597 & 200 & $\begin{array}{l}\text { Provavelmente a mesma densidade do Paramá } \\
\text { Ocidental }\end{array}$ \\
\hline $\begin{array}{l}\text { Costa oriental de Nica- } \\
\text { rágua e Honduras }\end{array}$ & 180.000 & 1.180 & 100 & $\begin{array}{l}\text { Densidade de Mosquito agora é 55; nativa } \\
\text { foi certamente o dobro }\end{array}$ \\
\hline Costa norte de Honduras & 25.000 & 500 & 50 & $\begin{array}{l}\text { Densidade Jicaque, } 20 \text { em 1674; densidade } \\
\text { Paya, } 50 \text { em } 1800\end{array}$ \\
\hline $\begin{array}{l}\text { Terras Altas de Hondu- } \\
\text { ras e El Salvador }\end{array}$ & 187.500 & 750 & 250 & $\begin{array}{l}\text { Densidade moderna dos Lenca ao redor de } \\
\text { 190; Kroeber dá } 292 \text { para El Salvador }\end{array}$ \\
\hline $\begin{array}{l}\text { Total para América } \\
\text { Central }\end{array}$ & \multicolumn{4}{|c|}{$736.500 \quad 3.900$} \\
\hline $\begin{array}{l}\text { Antilhas } \\
\text { Cuba }\end{array}$ & 80.000 & 1.147 & 69 & Rosenblat \\
\hline Jamaica & 40.000 & 115 & 348 & Rosenblat \\
\hline Bahamas & 20.000 & 114 & 175 & Metade da estimativa nativa \\
\hline Haiti e Santo Domingo & 100.000 & 767 & 555 & Rosenblat \\
\hline Porto Rico & 50.000 & 90 & 555 & $\begin{array}{l}\text { Rosenblat; De Hostos (Handbook, v. 4), deu } \\
200.000 \text {. Algumas estimativas chegaram até } \\
600.000\end{array}$ \\
\hline Baixas Antilhas & 35.000 & 70 & 500 & $\begin{array}{l}2.000 \text { em Saint Vicent em } 1700 \text {; se } 3.000 \\
\text { são nativos, a densidade de Saint Vicent é } \\
750 \text {, a densidade da Dominica é } 375\end{array}$ \\
\hline Total para Antilhas & 225.000 & \multicolumn{3}{|l|}{2.303} \\
\hline
\end{tabular}

ção que pode se agregar em grupos sóciopolíticos. Supondo que os presentes números são aproximadamente corretos, as densidades parecem variar significativamente entre os grupos culturais. Considerando os Andes centrais como medida padrão, estima-se que têm 44 vezes a densidade do arquipélago chileno, 14 a 40 vezes a densidade das outras tribos Marginais, 20 vezes a densidade dos povos da Floresta Tropical, e cerca de 2 vezes a densidade do Caribe, das terras altas da Colômbia, e da América Central.

Em termos ecológicos, as maiores densidades estavam nos Andes semi-áridos onde a subsistência baseava-se na agricultura intensiva, com irrigação e fertilizantes. Foi estimado que nos Andes meio alqueire de terra cultivada era necessária para sustentar cada pessoa, em contraste à necessidade de um alqueire no México e nos Estados Unidos Oriental (Kroeber 1939: 146-147, 163) e 7/10 de alqueire em Yucatán (Ricketson e Ricketson 1937: 16-17). As outras maiores densidades estavam na área ao redor do Caribe, onde as pessoas se apoiavam nas fontes marinhas e na agricultura. A situação é comparável à costa pacífica da América do Norte que, apesar da ausência de agricultura, tinha uma das populações mais densas do continente. Ao redor do Caribe, as fontes adicionais agrícolas sustentavam muito mais pessoas do que as costas da América do Norte. As áreas da costa e dos 
rios das Guianas e do Brasil eram mais raramente povoadas do que a área ao redor do Caribe, provavelmente por causa da baixa intensidade da agricultura. Tem-se a impressão de que vastas regiões de terras, potencialmente aráveis, jamais foram utilizadas e de que a população poderia ter estado se expandindo no período da conquista. Nas terras de savana, ao redor das bacias do Amazonas e do Orinoco, e na parte do Brasil oriental e do Grande Chaco, onde as raízes tropicais não podiam crescer e, onde as tribos eram caçadoras-coletoras, a população era extremamente esparsa. A densidade mais baixa estava nas planícies da Argentina que, embora bem adaptada para animais e para a agricultura de arado, não serviam para os métodos agrícolas dos índios.

\section{Tendências populacionais}

A população nativa da América do Sul está estimada em cerca de 9.000.000, dos quais aproximadamente a metade estava nos Andes Centrais (Tabela 3). Atualmente, cerca de 7.000 .000 de pessoas são classificadas como índios, especialmente por causa de razões culturais (algumas estimativas dobram este número). Há muitos milhões de caboclos, crioulos e mestiços de vários tipos que, embora predominantemente índios em sua raça, não são classificados como índios no censo. Biologicamente, há mais de 7 milhões de pessoas de ascendência índia. De fato, a raça índia é indubitavelmente tão numerosa quanto à época da conquista $\mathrm{e}$, ainda, provavelmente tem feito ganhos substanciais. $O$ ganho contudo é tributável inteiramente aos Andes. Em outros lugares, as populações foram reduzidas, embora não sempre tanto quanto o censo indique. A perda, que é primariamente uma função da intensidade e da duração do contato com o europeu e da densidade da população nativa, varia de área em área (Mapa 2).

A maior redução aconteceu ao longo do litoral e dos grandes rios para onde os europeus, tendo chegado de navio e mantendo contato com a pátria, invadiram com forças impressionantes. Os índios da costa do
Brasil, das Guianas, da Venezuela, da Colômbia, da América Central e do Equador, embora numerosíssimos, foram rapidamente derrotados; ao longo dos rios Amazonas e Orinoco, eles tiveram um declínio vertiginoso. Nestas áreas seu lugar foi parcialmente tomado por negros vindos da África. Na maioria das áreas do litoral e dos rios, a própria identidade das tribos nativas é duvidosa. Nas ilhas do Caribe, consideradas inteiramente litorâneas, os índios foram quase completamente extintos no período de um século e meio. Las Casas estimou que a população nativa de Porto Rico e da Jamaica havia diminuído de 3.000 .000 , um número extremamente alto, em 1509, para 200 em 1542. Como os Europeus penetraram o interior ao longo dos rios Amazonas e Orinoco, os índios foram gradualmente rendidos, alguns morrendo, outros culturalmente assimilados e misturando seu sangue ao sangue dos brancos e dos negros para formar populações mistas. Atualmente a sobrevivência principal dos índios se restringe às áreas de difícil navegação, ou seja, no grande $U$ que fica em torno da bacia Amazônica e inclui o encontro das águas do Amazonas e Orinoco, o Nordeste do Amazonas, Montaña, Mato Grosso, partes do Chaco e a planície no leste Brasileiro. Era esta a área das tribos Marginais e semi-Marginais que, na época pré-colombiana, havia ficado comparativamente não influenciada pelo tipo de cultura da floresta tropical que também chegava pelos rios. Em outros lugares, nas florestas tropicais e ao redor do mar do Caribe, os índios sobreviventes hoje vivem principalmente nas áreas inadequadas para a ocupação européia, como os pântanos do delta do Orinoco e da costa de Mosquito na Nicarágua e nas áreas montanhosas da Venezuela ocidental e da América Central (Tabela 3).

$\mathrm{Na}$ Argentina e no Uruguai onde a população nativa era esparsa, as tribos da costa foram as primeiros a sucumbir. Mais tarde, os europeus entraram no interior $\mathrm{e}$ encontraram o lugar adaptado para sua economia. Praticamente, os índios quase desapareceram. No Chile, a história se repetiu, com a exceção dos Araucano, os quais, empurrados para o sul, mas sem se renderem, 


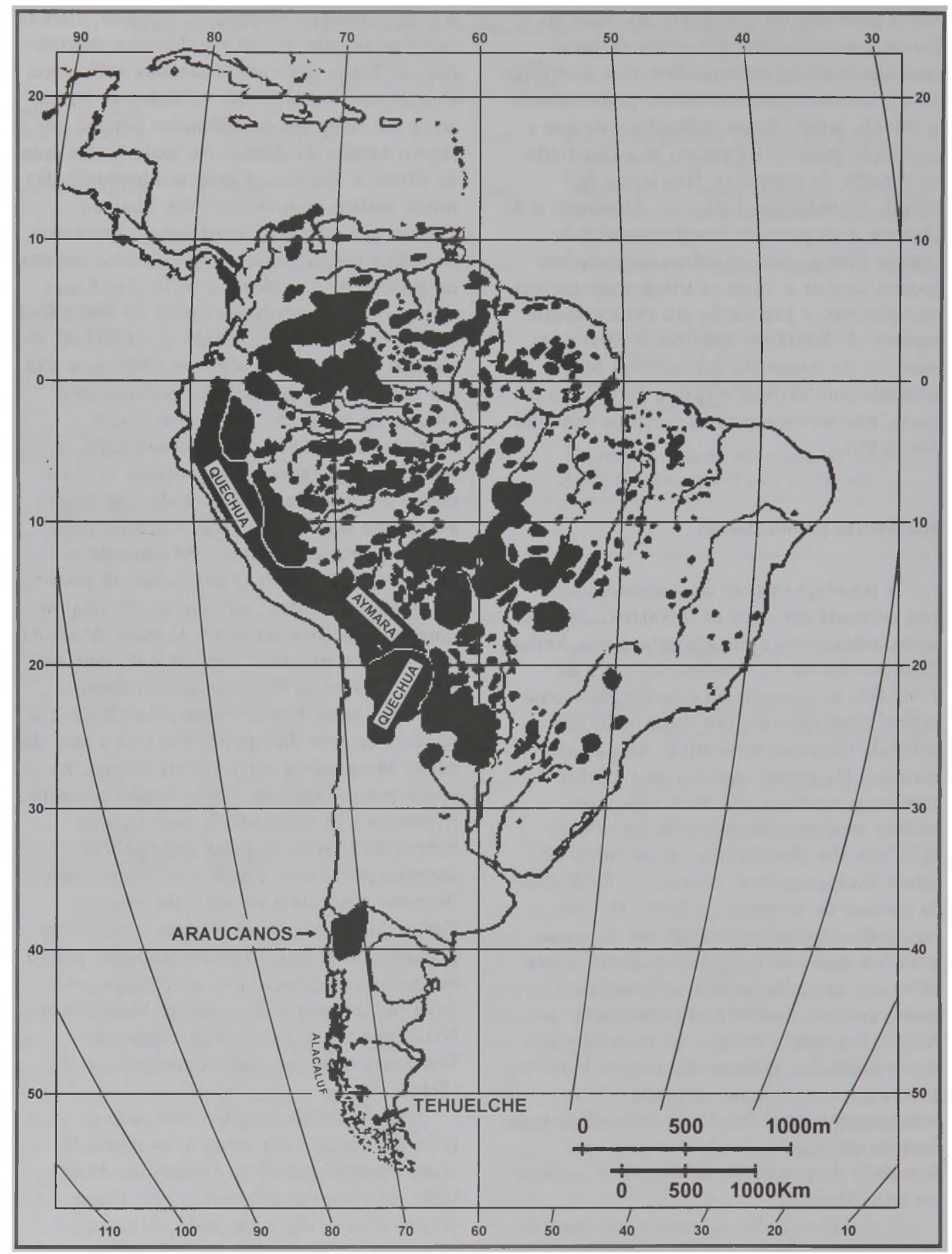

Mapa 2 
foram finalmente isolados numa reserva indígena.

Havia inúmeros fatores para tal declínio e seu funcionamento nas várias localidades produziu curvas populacionais dissimiles (veja Rosenblat 1945). As doenças européias, muito devastadoras onde havia grandes concentrações de índios, como nas missões e nas colônias forçadas, extinguiram dentro de um século ou dois algumas tribos, enquanto os vizinhos imediatos sobreviveram com certo vigor até os dias atuais. As guerras com os brancos e com as tribos que foram deslocadas pela Conquista foram desastrosas. Os índios também foram vítimas de uma ruptura na sua vida econômica e cultural. Talvez seja prematuro dizer se medidas sanitárias e os sistemas de reservas indígenas sustarão tal declínio.

Contrastando-se às demais regiões da América do Sul, os Andes, especialmente os Andes Centrais, atualmente contêm mais índios do que no período da Conquista. À semelhança de outros lugares, a costa sofreu mais diante dos contatos com o homem branco. Mais tarde, os brancos penetraram no interior e provavelmente a população se reduziu à metade. Esta população, numerosa em seu aspecto indígena, estável culturalmente e, até certo ponto, não afetada pelas epidemias, já se recuperou e atualmente está maior e em ascensão.

TABELA 3

\begin{tabular}{|c|c|c|c|}
\hline \multicolumn{4}{|c|}{ População Indígena da América do Sul } \\
\hline Localização & \multicolumn{2}{|c|}{$\begin{array}{lr}\text { População Indígena em } \\
1500 & 1940\end{array}$} & $\begin{array}{c}\text { Percentual da População } \\
\text { Nacional (1949) }\end{array}$ \\
\hline \multicolumn{4}{|l|}{ Nações Meridionais } \\
\hline Chile & 1.000 .000 & 200.000 & 9.0 \\
\hline Argentina & 300.000 & 120.000 & 1.0 \\
\hline Uruguai & 20.000 & Extintos & 0 \\
\hline Total & 1.320 .000 & 410.00 & \\
\hline $\begin{array}{l}\text { Nações Tropicais, Sub-tropicais e Cir } \\
\text { Paraguai }\end{array}$ & \multicolumn{2}{|c|}{ Nacões Tropicais, Sub-tropicais e Circum-Caribe } & 6.0 \\
\hline Brasil & 1.100 .000 & 500.000 & 11.0 \\
\hline Guianas & 90.000 & 11.000 & 2.4 \\
\hline Venezuela & 350.000 & 103.000 & 3.7 \\
\hline Antilhas & 300.000 & Extintos & 0 \\
\hline Terras Baixas da Colômbia & 350.000 & 105.000 & 5.7 \\
\hline Terras Altas da Colômbia & 800.000 & 60.000 & 3.2 \\
\hline Panamá & 70.000 & 42.000 & 9.0 \\
\hline Costa Rica & 40.000 & 3.000 & 0.6 \\
\hline Nicarágua, Honduras e El Salvador & 100.000 & 85.000 & 9.0 \\
\hline Total & 3.300 .000 & 969.000 & \\
\hline \multicolumn{4}{|l|}{ Nac̄oes das Terras Altas } \\
\hline Equador & 1.000 .000 & 960.000 & 50.0 \\
\hline Peru & 3.500 .000 & 2.800 .000 & 40.0 \\
\hline Bolívia & - & 1.800 .000 & 51.0 \\
\hline$\overline{\text { Total }}$ & 4.500 .000 & 5.560 .000 & \\
\hline Total, América do Sul & 9.120 .000 & 6.939 .000 & \\
\hline
\end{tabular}

